\title{
H3.3 Barcoding of Nucleus Accumbens Transcriptional Activity Identifies Novel Molecular Cascades Associated with Cocaine Self-administration in Mice
}

\author{
Mathieu E. Wimmer, ${ }^{1}$ Bruno Fant, ${ }^{2}$ Sarah E. Swinford-Jackson, ${ }^{2}$ Alexander Testino, ${ }^{2}$ Duncan Van Nest, ${ }^{2}$-Ted Abel, ${ }^{3}$ \\ and R. Christopher Pierce ${ }^{2}$ \\ ${ }^{1}$ Department of Psychology and Program in Neuroscience, Temple University, Philadelphia, Pennsylvania 19122, ${ }^{2}$ Department of Psychiatry, Center for \\ Neurobiology and Behavior, Perelman School of Medicine at the University of Pennsylvania, Philadelphia, Pennsylvania 19104, and ${ }^{3}$ Department of \\ Molecular Physiology and Biophysics, Iowa Neuroscience Institute, University of Iowa, Iowa City, Iowa 52242
}

\begin{abstract}
Although numerous epigenetic modifications have been associated with addiction, little work has explored the turnover of histone variants. Uniquely, the $\mathrm{H} 3.3$ variant incorporates stably and preferentially into chromatin independently of DNA replication at active sites of transcription and transcription factor binding. Thus, genomic regions associated with H3.3-containing nucleosomes are particularly likely to be involved in plasticity, such as following repeated cocaine exposure. A recently developed mouse line expressing a neuron-specific hemagglutinin (HA)-tagged H3.3 protein was used to track transcriptionally active sites cumulatively across $19 \mathrm{~d}$ of cocaine self-administration. RNA-seq and H3.3-HA ChIP-seq analyses were performed on NAcc tissue collected following cocaine or food self-administration in male mice. RNA sequencing revealed five genes upregulated in cocaine relative to food self-administering mice: Fosb, Npas4, Vgf, Nptx2, and Pmepa1, which reflect known and novel cocaine plasticity-associated genes. Subsequent ChIP-seq analysis confirmed increased H3.3 aggregation at four of these five loci, thus validating H3.3 insertion as a marker of enhanced cocaine-induced transcription. Further motif recognition analysis of the ChIP-seq data showed that cocaine-associated differential H3.3 accumulation correlated with the presence of several transcription factor binding motifs, including RBPJ1, EGR1, and SOX4, suggesting that these are potentially important regulators of molecular cascades associated with cocaine-induced neuronal plasticity. Additional ontological analysis revealed differential H3.3 accumulation mainly near genes involved in neuronal differentiation and dendrite formation. These results establish the H3.3-HA transgenic mouse line as a compelling molecular barcoding tool to identify the cumulative effects of long-term environmental perturbations, such as exposure to drugs of abuse.
\end{abstract}

Key words: ChIP-seq; EGR1; histone; RBPJ1; RNA-seq; SOX4

\section{Significance Statement}

Histone H3.3 is a core histone variant that is stably incorporated at active sites of transcription. We used a tagged version of H3.3 expressed exclusively in neurons to delineate active transcription sites following extended cocaine self-administration in mice. This approach revealed the cumulative list of genes expressed in response to cocaine taking over the course of several weeks. We combined this technique with RNA sequencing of tissue collected from the same animals $24 \mathrm{~h}$ after the last cocaine exposure. Comparing these datasets provided a full picture of genes that respond to chronic cocaine exposure in NAcc neurons. These studies revealed novel transcription factors that are likely involved in cocaine-induced plasticity and addiction-like behaviors.

\section{Introduction}

Epigenetic mechanisms transduce environmental stimuli to promote changes in chromatin structure that function to activate or

Received Jan. 3, 2019; revised April 17, 2019; accepted April 26, 2019

Author contributions: M.E.W., B.F., S.E.S.-J., T.A., and R.C.P. designed research; M.E.W., B.F., S.E.S.-J., A.T., and D.V.N. performed research; M.E.W., B.F., and S.E.S.-J. analyzed data; M.E.W., B.F., and S.E.S.-J. wrote the first draft of the paper; M.E.W., B.F., S.E.S.-J., T.A., and R.C.P. edited the paper; M.E.W., B.F., S.E.S.-J., and R.C.P. wrote the paper. repress gene transcription (Jaenisch and Bird, 2003). Posttranslational modifications to histones and chromatin remodeling are dynamic epigenetic processes that alter access of transcriptional 
machinery to promoter regions, thereby regulating patterns of gene expression (Strahl and Allis, 2000; Berger, 2007). A growing body of evidence indicates that chromatin remodeling, including stable enzymatic modifications of DNA and histone proteins, is associated with persistent changes in gene expression that may underlie drug addiction (Renthal and Nestler, 2008; Maze and Nestler, 2011; Pierce et al., 2018).

The composition of nucleosomes is dynamic in that canonical histone proteins can be replaced by variants. Histone $\mathrm{H} 3$ has three variants in the mouse: H3.1 and H3.2, which differ by only one amino acid; and H3.3, which differs by four amino acids from H3.2. Despite this high sequence similarity, only H3.3 incorporates into chromatin independently of replication (Bano et al., 2017). Furthermore, in contrast to H3.1 and H3.2, H3.3 has been shown to preferentially incorporate into active regions of chromatin (Ahmad and Henikoff, 2002; Goldberg et al., 2010). In this manner, genomic regions can be "barcoded" with H3.3, thereby serving as an archive of transcriptionally active states (Hake and Allis, 2006). Here, we used a mouse line expressing tagged histone H3.3 only in neurons, which obviates the influence of other cell types, such as glia (McNally et al., 2016). The CaMKII $\alpha$ promoter was used to drive neuronal expression of the transgene in the NAcc, where $>90 \%$ of neurons are GABAergic medium spiny projection neurons and all neuronal subtypes express abundant CaMKII $\alpha$ (Groves, 1983; Solà et al., 1999; Haber, 2003; Anderson et al., 2008). Moreover, the tetracycline transactivator system was used to limit H3.3-hemagglutinin (HA) expression to adulthood, thereby circumventing any potentially deleterious effects of expression during development. RNA sequencing as well as sequencing following immunoprecipitation of H3.3-HA-containing nucleosomes were used to make unbiased determinations of changes in transcriptional activity in barcoded accumbens neurons following cocaine versus food self-administration. Because H3.3-HA incorporation into chromatin is stable, the H3.3chromatin immunoprecipitation sequencing (ChIP-seq) results reflect a readout of all transcriptional activity throughout cocaine self-administration. These findings were compared with RNAseq results, which represent a snapshot in time: specifically, $24 \mathrm{~h}$ following the cessation of cocaine self-administration, which is a common time point used in molecular studies focused on repeated cocaine administration (Renthal et al., 2009; Maze et al., 2010; Feng et al., 2014). Our results identified both known and novel molecular pathways associated with cocaine selfadministration, which could be exploited to develop novel cocaine addiction therapeutics.

\section{Materials and Methods}

Subjects. The creation of the tetO-H3.3-HA mouse line is described in detail previously (McNally et al., 2016). Briefly, a mouse-codon optimized N-terminal tagged H3.3-HA sequence from GeneArt (Thermo Fisher Scientific) was cloned into the MM400 plasmid containing the tetO tetracycline-regulatable enhancer element. Four founder lines were generated and crossed with C57BL/6J mice expressing the CaMKII $\alpha$-tTA transgene (Mayford et al., 1996). Littermates carrying only a single transgene served as controls. The tetO-driven construct rapidly reduces expression of the transgene after exposure to doxycycline (Bejar et al., 2002; Kelly et al., 2009). H3.3-HA transgene expression was temporally restricted by raising animals on doxycycline. Thus, both sire and dam were fed a doxycycline-containing diet $(200 \mathrm{mg} / \mathrm{kg})$ during breeding with the dam maintained on this diet through weaning at $21 \mathrm{~d}$.

Adult male transgenic and control mice were group housed on a 12:12 light/dark cycle (lights on at 7:00 A.M.), with water access ad libitum. Mice were restricted to $90 \%$ of free-feeding weight throughout all behavior experiments, except while recovering from surgery during which food was available ad libitum. All experiments, which were approved by the Institution of Animal Care and Use Committee of the University of Pennsylvania and conducted in accordance with the National Institutes of Health guidelines, were performed during the light cycle.

Self-administration. All surgical procedures and operant experiments are similar to our previous work (Briand et al., 2014; Ortinski et al., 2015). At $\sim 60 \mathrm{~d}$ of age, mice were initially trained to spin a wheel manipulandum (Med Associates; one-quarter turn equaled an operant response) for food pellets (Bio-Serv) under a fixed ratio 1 (FR1) schedule of reinforcement. After $10 \mathrm{~d}$ of food self-administration, all subjects underwent surgery for the implantation of a jugular catheter. After $7 \mathrm{~d}$ of recovery, some animals were returned to food self-administration, whereas others switched to respond for intravenous cocaine infusions ( $0.5 \mathrm{mg}$ /infusion) also using an FR1 schedule. Mice were limited to a maximum of 30 cocaine infusions per daily $2 \mathrm{~h}$ self-administration session. The day after the last of $19 \mathrm{~d}$ of cocaine (or $29 \mathrm{~d}$ of food) selfadministration, the mice were killed and the NAcc dissected. The NAcc from each hemisphere was processed separately. One unilateral NAcc sample per subject was immediately processed for RNA-sequencing (RNA-seq) analysis. The other unilateral accumbens punches were pooled from all subjects in respective cocaine or food groups for chromatin immunoprecipitation.

RNA-seq. For each sample ( $n=4$ in both conditions, food and cocaine), total RNA was extracted using the RNeasy Mini Kit (QIAGEN) according to the manufacturer's instructions. RNA quality was assessed on a BioAnalyzer 2100 (Agilent Technologies), and sequencing libraries were prepared using the TruSeq RNA Library Prep Kit (Illumina) according to the manufacturer's instructions. Libraries were sequenced by the University of Iowa Genomics Core. Raw.fastq sequencing files were then quality-filtered, trimmed, and aligned on the Grcm38 mouse reference genome using the STAR aligner (https://github.com/alexdobin/ STAR) (Dobin et al., 2013). Principal component analysis was performed in $\mathrm{R}$, during which one cocaine sample was revealed to account for the majority of the variability explained by the first principal component, and was therefore eliminated from further analyses. Differential expression analysis was performed using the DESeq package (Love et al., 2014); a $q$ value threshold ( $p$ value adjusted to account for false detection rate according to the Benjamini-Hochberg method) of 0.1 was used to determine significance.

ChIP and sequencing. ChIP was performed as previously described (McNally et al., 2016). Briefly, for each group (food self-administration or cocaine self-administration), pooled punches of the accumbens were incubated in 2\% PFA for $10 \mathrm{~min}$ at room temperature, followed by the addition of $100 \mu \mathrm{l} 1 \mathrm{M}$ glycine to quench the reaction. Punches were then manually disrupted using disposable microhomogenizers, and the nuclei were lysed. Chromatin was then sheared using a Bioruptor (Diagenode), with four $10 \mathrm{~min}$ cycles of $30 \mathrm{~s}$ on and $30 \mathrm{~s}$ off. After centrifugation to eliminate debris, samples were incubated with $2 \mu \mathrm{g}$ HA antibody (Roche Diagnostics, clone $3 \mathrm{~F} 10$ ) at $4^{\circ} \mathrm{C}$ overnight. The following day, samples were incubated in a $50 \%$ slurry of Protein G Agarose beads (Pierce, \#20398) for $2 \mathrm{~h}$ at $4^{\circ} \mathrm{C}$. Beads were washed in low-salt buffer, high-salt buffer, and $1 \times$ TE buffer. After elution in $1 \%$ SDS/0.1 $\mathrm{M} \mathrm{NaHCO}_{3}$, samples were reverse crosslinked overnight at $65^{\circ} \mathrm{C}$. Samples were then treated with proteinase $\mathrm{K}$, and DNA was purified using the QIAGEN Qiaquick PCR Purification Kit and eluted in $100 \mu \mathrm{l}$ water.

Sequencing libraries were prepared using the TruSeq ChIP Library Preparation Kit (Illumina) following the manufacturer's instructions, and using $10 \mathrm{ng}$ of input immunoprecipitated DNA. Libraries were then sequenced by the University of Iowa Genomics Core. Raw.fastq sequencing files were then quality-filtered, trimmed, and aligned on the Grcm38 mouse reference genome using the STAR aligner (https://github.com/ alexdobin/STAR) (Dobin et al., 2013). Differential peak calling was then performed using the MACS software (http://liulab.dfci.harvard.edu/ MACS/index.html) with a $p$ value cutoff of 1e-5 (Zhang et al., 2008), and peaks were annotated using the HOMER software (http://homer.ucsd. edu/homer/) (Heinz et al., 2010).

Binding motif recognition and ontology analysis. De novo binding motif recognition was performed on the set of all transcript promoters (permissively defined here as a $2 \mathrm{~kb}$ region centered around the transcription 
start site [TSS]) for which differential H3.3 aggregation was detected between cocaine ChIP-seq and food ChIP-seq using the HOMER software. As advised by the authors of the software, only binding motifs with $p<10 \mathrm{e}-9$ were considered, as discrepancies between motif structures and specificities at higher $p$ values became too high. Ontology analysis was performed on the same transcript set using the HOMER software, and the DAVID platform (https://david.ncifcrf.gov/).

RNA extraction and $q P C R$. We extracted RNA using the RNeasy kit (QIAGEN) according to the manufacturer's instructions. RNA concentration and purity were quantified by NanoDrop spectrophotometry (Thermo Fisher Scientific). Generation of cDNA was performed using the SuperScriptIII Reverse Transcriptase kit (Thermo Fisher Scientific) with $80 \mathrm{ng}$ of RNA as template. Reactions were prepared in 96-well optical reaction plates $(\mathrm{ABI})$ with optical adhesive covers $(\mathrm{ABI})$ using TaqMan Fast Universal PCR Master Mix (Invitrogen). Three technical replicates were used for each animal. Reactions were performed in the Step One Plus with an initial incubation at $95^{\circ} \mathrm{C}$ for $10 \mathrm{~min}$, and 40 subsequent cycles of $95^{\circ} \mathrm{C}$ for $15 \mathrm{~s}, 60^{\circ} \mathrm{C}$ for $30 \mathrm{~s}$. The TaqMan probes used in these experiments were as follows: Npas4, Mm01227866_g1; Nptx2, Mm00479438_m1; Pmepal, Mm00452230_g1; Vgf, Mm01204485_s1; Fosb, Mm00500401_ m1; Gapdh, Mm99999915_g1. $\Delta \mathrm{C}_{\mathrm{t}}$ values were corrected using housekeeping gene expression levels for each sample, and fold change was calculated as $2 \exp \left(-\Delta \Delta \mathrm{C}_{\mathrm{t}}\right)$. The data were analyzed with one-tailed $t$ tests and presented as the mean for the biological replicates, with $n$ being equal to the number of biological replicates (i.e., the number of mice examined).

Immunohistochemistry. Naive adult CaMKII $\alpha$-tTA $\mathrm{x}$ tetO-H3.3HA or WT mice were perfused with $60 \mathrm{ml}$ of ice-cold PBS, $\mathrm{pH}$ 7.4, followed by $30 \mathrm{ml}$ of $4 \%$ PFA dissolved in ice-cold PBS. Brains were removed and placed in $4 \%$ PFA for $24 \mathrm{~h}$ before storage in 30\% sucrose dissolved in PBS with $1 \%$ sodium azide. Coronal sections $(30 \mu \mathrm{m})$ through the NAcc were taken using a vibratome (Technical Products International) and mounted directly onto polarized glass slides. Dry slides were permeabilized in $0.1 \%$ Triton in PBS for 5 min, quenched with $1 \%$ hydrogen peroxide in PBS for $15 \mathrm{~min}$, and washed in PBS before blocking in $0.3 \%$ Triton and $8 \%$ normal donkey serum in PBS for $50 \mathrm{~min}$. Slides were incubated in primary antibody (rat anti-HA, 1:500, 3F10, Roche Diagnostics; rabbit anti-NeuN, 1:500, ab177487, Abcam) in 0.3\% Triton in PBS overnight at $4^{\circ} \mathrm{C}$. Slides were washed in PBS before and after incubation in fluorescent secondary antibody (donkey anti-rat AlexaFluor488, 1:1000, A-21208, Thermo Fisher Scientific; donkey anti-rabbit AlexaFluor-594, 1:1000, A-21207, Thermo Fisher Scientific) for $2 \mathrm{~h}$ at room temperature. Finally, slides were coverslipped with Vectashield mounting medium (Vector Laboratories) and imaged for HA expression or colabeling of HA and the neuronal marker NeuN using fluorescent confocal microscopy at $10 \times, 20 \times$, and $40 \times$ magnification.

Experimental design and statistical analyses. For behavioral experiments, all animals first underwent $10 \mathrm{~d}$ of food self-administration. After catheterization implant surgery, animals were randomly assigned to either be placed back on food self-administration or begin cocaine self-administration. ANOVAs were used for all analyses of selfadministration data with days as the within-subject factor and group (food or cocaine) as the between-subject factor. If a significant interaction was found, Tukey's post hoc tests were conducted. All analyses of sequencing data are described in detail above and in Results. For all molecular analyses, one side of the brain was used for RNA seq and the contralateral side was used for ChIP seq with $n=3$ or 4 per group. Student's $t$ tests were used to analyze qPCR data.

\section{Results}

\section{Neuron-specific H3.3-HA incorporation does not alter food} or cocaine self-administration

Animals carrying both the tTA transgene driven by the CaMKII promoter and the tetO-H3.3-HA transgene were killed, and brain tissue was collected from drug-naive adult animals. Some of the brains were sectioned and processed for immunostaining using an anti-HA antibody. These experiments revealed extensive expression of the HA-tagged H3.3 protein in the NAcc (Fig. 1A).
We also used an anti-HA antibody to immunoprecipitate chromatin from the NAcc to examine whether the tagged H3.3 proteins were incorporated into neuronal nucleosomes. We found that H3.3-HA abundance was higher at neuronal loci, including $\mathrm{Nr} 4 \mathrm{a} 1$ and Snap25 compared with genes expressed in glia or liver $\left(F_{(4,20)}=8.967, p=0.0130\right)$ (Fig. $\left.1 B\right)$, indicating that the HAtagged $\mathrm{H} 3.3$ proteins are incorporated into nucleosomes primarily in neurons within the NAcc. Neuronal expression of H3.3-HA protein and specificity of the HA antibody were confirmed by immunohistochemistry. We observed strong colocalization of HA and the neuronal marker NeuN (Fig. 1C), supporting neuronal expression of H3.3-HA protein. Importantly, expression of the H3.3-HA tag did not alter food training or cocaine selfadministration relative to littermates carrying only one of the two transgenes (Fig. 1D). For food training, there was no main effect of genotype $\left(F_{(1,81)}=0.039, p=0.8470\right)$, a main effect of day $\left(F_{(9,81)}=6.366, p<0.0001\right)$, and no genotype $\times$ day interaction $\left(F_{(9,81)}=0.908, p=0.5227\right)$. For cocaine self-administration, there was no main effect of genotype $\left(F_{(1,162)}=0.119, p=\right.$ $0.7383)$, no main effect of day $\left(F_{(18,162)}=0.848, p=0.6417\right)$, and no genotype $\times$ day interaction $\left(F_{(18,162)}=0.516, p=0.9480\right)$.

\section{Cocaine versus food self-administration in mice elicits corresponding gene expression changes and $\mathrm{H} 3.3$ deposition in promoters}

H3.3-HA mice were trained to self-administer food or cocaine, and the NAcc was harvested for subsequent molecular analyses. One side of the brain was immediately prepared for H3.3-HA ChIP sequencing; the contralateral side of the brain was flash frozen, stored at $-80^{\circ} \mathrm{C}$, and later prepared for RNA sequencing experiments (Fig. 2A). There was no difference between food and cocaine groups during food training or subsequent selfadministration (Fig. 2B). For food training, there was no main effect of group $\left(F_{(1,54)}=2.72, p=0.1502\right)$, a main effect of day $\left(F_{(9,54)}=2.925, p=0.0067\right)$, and no group $\times$ day interaction $\left(F_{(9,54)}=0.545, p=0.8351\right)$. For food versus cocaine selfadministration, there was no main effect of reinforcer $\left(F_{(1,108)}=\right.$ $0.480, p=0.5145)$, no main effect of day $\left(F_{(18,108)}=0.933, p=\right.$ $0.5414)$, and no day $\times$ reinforcer interaction $\left(F_{(18,108)}=0.882\right.$, $p=0.6013)$.

To examine the molecular consequences of cocaine exposure, RNA sequencing and H3.3-HA ChIP sequencing were performed on the NAcc of H3.3 mice that self-administered cocaine $(n=3$ for RNA-seq, $n=4$ contralateral for ChIP-seq) or food ( $n=4$ for RNA-seq, $n=4$ contralateral for ChIP-seq). Principal component analysis of RNA-seq data revealed that cocaine and food samples were well separated along the second principal component axis (Fig. 2C). Annotation of the ChIP-seq data showed that detected H3.3-HA peaks enriched in the cocaine group compared with the food group were disproportionally located in promoters (Fig. $2 D$; cocaine $=18.30 \%$, food $=8.12 \%$, enriched in cocaine vs food peaks $=22.45 \%$ vs $1.1 \%$ for a random distribution). Furthermore, a similar pattern emerged for exon regions (Fig. $2 D ;$ cocaine $=5.35 \%$, food $=6.31 \%$, enriched in cocaine vs food peaks $=6.12 \%$ vs $2 \%$ for a random distribution). This is in line with published findings using a similar transgenic line of tagged H3.3 histone proteins (Maze et al., 2015).

Analysis of the RNA-seq data revealed that 5 genes were overexpressed (none repressed) between the cocaine and the food groups: Pmepal, Vgf, Nptx2, Npas4, and Fosb (Table 1). qPCR confirmed significant overexpression in cocaine-trained versus food-trained mice for Npas4 $\left(t_{(1,5)}=2.878, p=0.0173\right)$ and $N p t x 2\left(t_{(1,6)}=2.685\right.$, $p=0.0187)$ as well as overexpression that did not reach significance 
criteria for $\operatorname{Vg} f\left(t_{(1,6)}=1.022, p=0.1730\right)$, Pmepal $\left(t_{(1,6)}=1.101, p=0.1566\right)$, and Fosb $\left(t_{1,5}=1.119, p=0.1561\right.$; Fig. $\left.2 E\right)$. Cross-referencing this gene list with the ChIP-seq data showed that cocainespecific H3.3-HA accumulation was present at the promoter of three of these candidates (Vgf, Nptx2, and Npas4), which is consistent with increased transcription (Fig. 3-1, available at https:// doi.org/10.1523/JNEUROSCI.0015-19. 2019.f3-1). Although there was no H3.3-HA differential presence at the immediate promoter of Fosb, extensive H3.3 accumulation was detected upstream ( -9.5 to $-10 \mathrm{~kb}$; Fig. 3-1, available at https://doi.org/10.1523/JNEUROSCI. 0015-19.2019.f3-1) in an Ensemblannotated promoter flank region, possibly indicative of a distal promoter. The only differentially expressed gene that did not exhibit any change in $\mathrm{H} 3$.3-HA occupancy between the two groups was Pmepa1, a microglia-specific gene (Butovsky et al., 2014). Hence, it is not surprising that neuronal H3.3-HA dynamics at this locus did not mirror increased transcription in our neuron-specific mouse model. Collectively, these results confirm that $\mathrm{H} 3.3$ accumulation acts as a reliable proxy for transcriptional activity.

\section{Cocaine-associated H3.3-HA}

accumulation identifies putative roles for and regulators of cocaine-induced transcripts

The H3.3-HA mouse model uniquely tracks transcription events in a cumulative fashion: H3.3 insertion is stable and continues barcoding a transcriptionally active locus, even after the gene is no longer expressed. Thus, early or transient responses to cocaine exposure can be tracked by monitoring $\mathrm{H} 3.3$ genomic insertion using the H3.3-HA-tagged transgene. We used this approach to isolate a more comprehensive set of genes that may have played a role during the $19 \mathrm{~d}$ of cocaine exposure to investigate their potential functions as well as their putative regulators. H3.3 insertion was most correlated with transcription when it occurred in promoter regions and/or close to the TSS (Daury et al., 2006; Maze et al., 2015; McNally et al., 2016). Therefore, we focused our analysis on cocaine-specific H3.3 differential accumulation peaks within $1 \mathrm{~kb}$ of annotated TSSs (Fig. $3 A$; Fig. 3-1, available at https://doi.org/ 10.1523/JNEUROSCI.0015-19.2019.f3-1). This conservative analytical method yielded a set of $\sim 2100$ H3.3-associated transcripts, which were the bases of the ontology and binding transcription factors analyses. The former revealed several en-

\section{CaMKII-tTA line $x$ tet-O H3.3-HA line (tissue collected from drug naive mice)}
A Immunohistochemistry anti-HA antibody
B Chromatin Immunoprecipitation anti-HA antibody
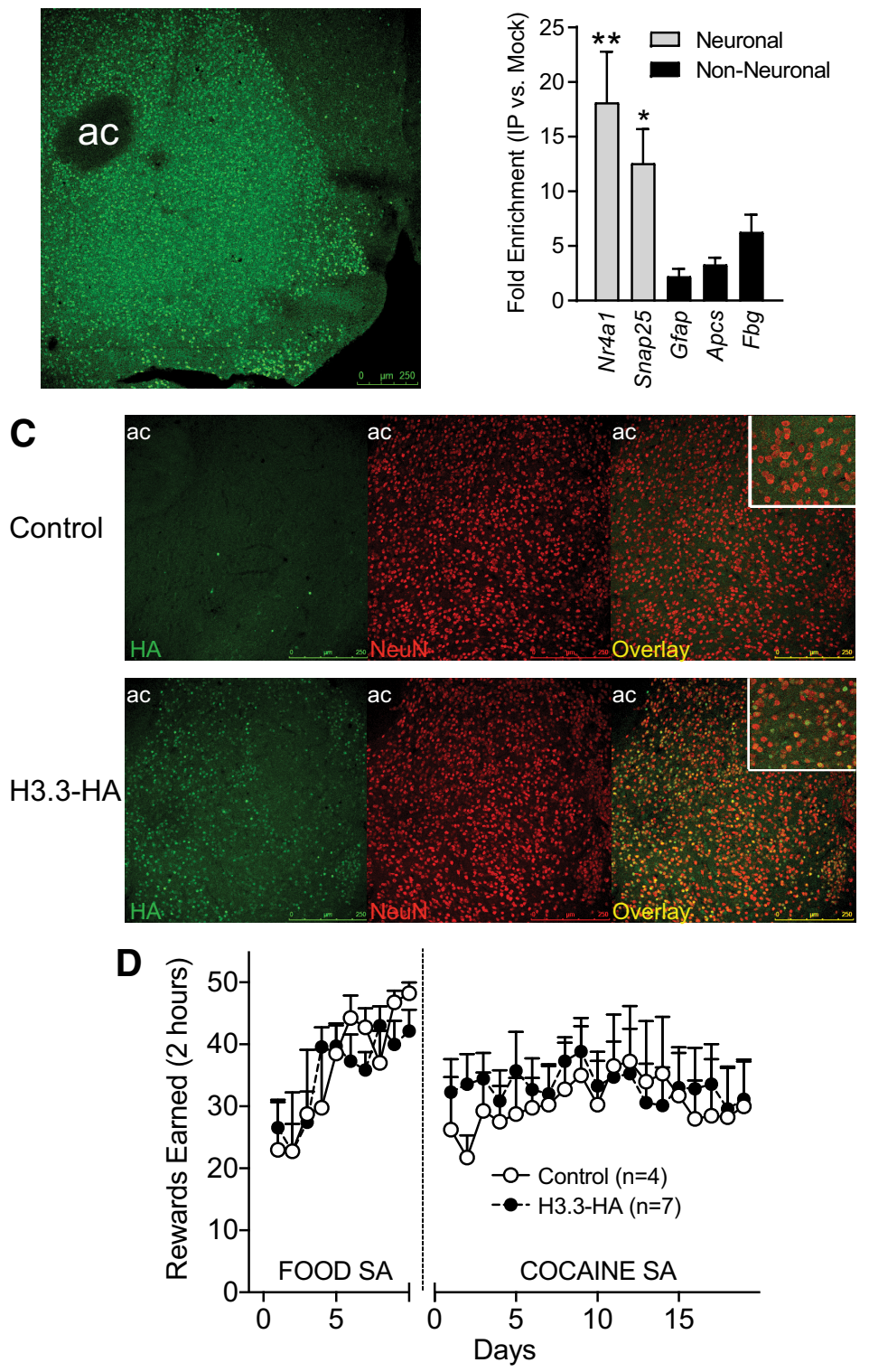

Figure 1. H3.3-HA incorporation is neuron-specific and does not alter food and cocaine self-administration. H3.3-HA-tagged mice were generated by crossing the $\mathrm{CaMKII-tTA}$ and tet- $\mathrm{OH}$ 3.3-HA lines. Tissue was collected for either immunohistochemistry or ChIP to validate expression of the transgene in neurons of the NAcc. $\boldsymbol{A}$, The tagged version of H3.3 is expressed in the NAcc of transgenic H3.3-HA animals. Scale bar, $250 \mu \mathrm{m}$. ac, Anterior commissure. $\boldsymbol{B}$, The HA-tagged version of H3.3 is more abundant near genes expressed in neurons compared with glia- and liver-specific genes. ${ }^{* *} p<0.05$, comparing Nr4a1 to Gfap, Apcs, and Fbg. ${ }^{*} p<0.05$, comparing Snap25 to Gfap, Apcs, and Fbg. C, Immunohistochemistry from NAcc of WT and H3.3-HA mice showing expression of the HA tag (green, left), the neuronal marker NeuN (red, middle), and the overlay (yellow, right). Insets in the overlay represent $40 \times$ magnification of cells colabeled for $\mathrm{HA}$ and NeuN. HA is selectively expressed in $\mathrm{H} 3.3-\mathrm{HA}$ mice and is coexpressed with a neuronal marker. Scale bar, $250 \mu \mathrm{m}$, ac, Anterior commissure. D, Control and transgenic H3.3-HA mice were given access to food self-administration for $10 \mathrm{~d}$. Following catheter implantation and recovery, animals had access to cocaine self-administration $(0.5 \mathrm{mg} / \mathrm{kg} /$ infusion$)$ in the same operant chambers. Transgenic and control animals earned the same number of rewards during both food and cocaine self-administration sessions. riched terms related to cell development, including neurogenesis and neuronal differentiation, dendrite formation and structure, as well as morphine addiction (Fig. $3 B$ ). Transcription regulation was also an enriched ontology term, indicating that the set of 


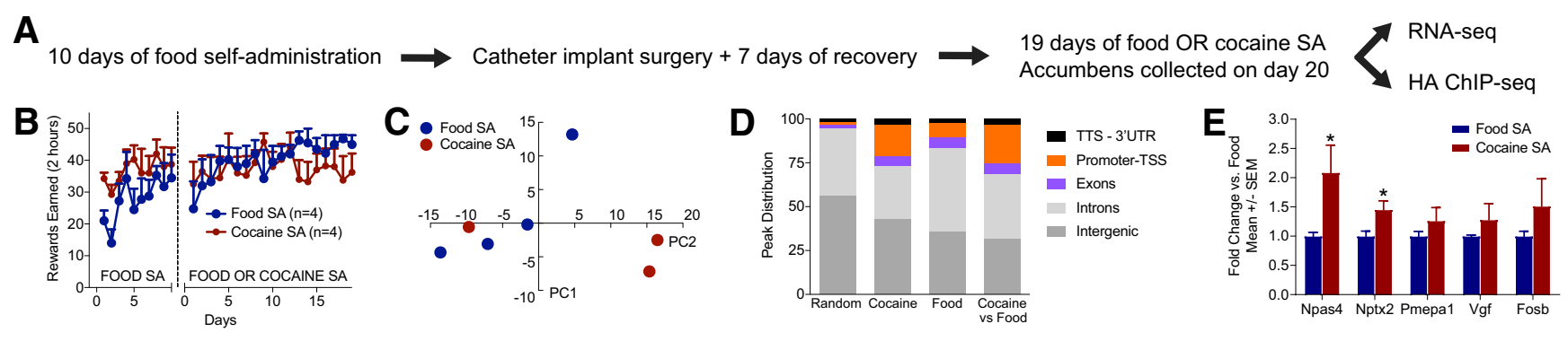

Figure 2. Changes in gene expression in cocaine versus food self-administering mice correlate with $\mathrm{H} 3.3$ deposition in promoters. $\boldsymbol{A}$, H3.3-HA animals self-administered food for 10 consecutive days. Animals were implanted with catheters and given access to either food or cocaine for an additional $19 \mathrm{~d}$ following recovery from surgery. Twenty-four hours after the last operant session, NAcc tissue was collected. One side of the brain was processed for RNA-seq, and the other side was prepared for HA ChIP-seq. B, Transgenic HA-tagged male mice earned the same number of rewards (food or cocaine) both during the training phase, when all mice received food, and during the extended access to either food or cocaine. $\boldsymbol{C}$, Principal component analysis of RNA-seq data revealed that principal component 2, which accounts for $16.9 \%$ of variability, is likely cocaine exposure. D, Distribution of annotated peaks resulting from the $H A$ ChIP analysis revealed a preferential deposition of the tagged $\mathrm{H} 3.3$ protein near promoter and exon regions compared with a random distribution genomewide. $\boldsymbol{E}$, 0 verexpression of 5 genes in cocaine-trained versus food-trained mice (Table 1 ) is confirmed by $q \mathrm{PCR}$. ${ }^{*} p<0.05$ versus food.

Table 1. Differentially expressed genes in H3.3-HA mice after $19 \mathrm{~d}$ of cocaine selfadministration $^{a}$

\begin{tabular}{lllll}
\hline Gene name & Ensembl ID & Fold change & $p$ & Adjusted $p^{b}$ \\
\hline Pmepa1 & ENSMUSG00000038400 & 1.599 & $2.749 \mathrm{E}-06$ & 0.0202 \\
Vgf $^{f}$ & ENSMUSG00000037428 & 1.557 & $4.697 \mathrm{E}-06$ & 0.0202 \\
Nptx2 $^{c}$ & ENSMUSG00000059991 & 1.860 & $4.640 \mathrm{E}-06$ & 0.0202 \\
Npas4 $^{c}$ & ENSMUSG00000045903 & 2.347 & $2.646 \mathrm{E}-06$ & 0.0202 \\
Fosb $^{c}$ & ENSMUSG00000003545 & 1.646 & $1.375 \mathrm{E}-05$ & 0.0472 \\
\hline
\end{tabular}

${ }^{a}$ Differential expression was assessed using the DESeq package in $\mathrm{R}$.

${ }^{b}$ The adjusted $p$ value was computed using the Benjamini-Hochberg procedure.

'Differential aggregation of H3.3 has been shown near the TSS using ChIP-seq data.

candidate genes might not only encompass effector genes but also their upstream regulators.

A de novo binding motif recognition analysis was also performed on the promoters of the $\sim 2100$ transcript set. Four motifs that could be associated with known transcription factors were overrepresented in the cocaine-enriched loci (Fig. 3C): a TC CCACATCGCT motif potentially bound by Rbpj1 and $\operatorname{Egr} 1$ ( $p=$ 1e-9), a GGAACAAAAGAG motif associated with the Sox factor family and Sox4 in particular $(p=1 \mathrm{e}-9)$, a TGCAYAGKCACA $R f x 5$-linked motif ( $p=1 \mathrm{e}-9)$, and a CAATADAATGAA motif associated with the Hoxa/b/d family, particularly Hoxd10 ( $p=1 \mathrm{e}$ $9)$. Overrepresentation of these motifs suggests that their associated transcription factors may play an important regulatory role during cocaine self-administration.

\section{Discussion}

Our results demonstrate that $\mathrm{H} 3.3-\mathrm{HA}$ transgenic mice can be used to uncover cumulatively active transcription throughout prolonged cocaine self-administration. Parallel RNA sequencing and H3.3-HA ChIP sequencing analyses identified four cocaineinduced transcriptionally active and overexpressed genes in neurons relative to mice that self-administered food. Motif recognition analyses of chromatin associated with $\mathrm{H} 3.3$ predicted putative binding motifs for several transcription factors, including Rbpj1, Egr1, and Sox4. Moreover, gene ontology suggested H3.3 accumulation near genes implicated in neuronal differentiation and dendrite formation as well as morphine addiction.

Several genes identified by our RNA-seq analysis as being overexpressed in the NAcc of mice self-administering cocaine relative to food have been previously identified as cocaine regulated. For example, a rich literature indicates that repeated cocaine causes a prolonged accumulation of FosB and its isoforms in the NAcc (Nestler, 2004; Chandra and Lobo, 2017). FosB tran- scription is promoted by the activation of the D1 dopamine receptor-cAMP-PKA-CREB pathway and, among other things, FosB enhances the transcription of BDNF, which increases dendritic spine density (Zhang et al., 2002; Mallei et al., 2018). The current finding that the transcription factor Npas4, which is a target of HDAC5 (Taniguchi et al., 2017), is overexpressed in the NAcc of cocaine self-administering mice is consistent with a recent study demonstrating that experimenter-delivered cocaine increased Npas4 expression in the NAcc (Taniguchi et al., 2017). Interestingly, conditional $\mathrm{KO}$ of accumbens Npas4 attenuated cocaine conditioned place preference in mice and produced modest decreases in cocaine self-administration, which may have been due to operant learning deficits (Taniguchi et al., 2017). We also observed higher gene expression of Nptx2 following cocaine versus food self-administration. Nptx2 (also known as Narp) is an immediate early gene that promotes AMPA receptor clustering at synapses (Pelkey et al., 2015), a process linked to cocaine-elicited behavioral plasticity (Pierce and Wolf, 2013). Previous work indicated that extinction training following cocaine selfadministration elevated mRNA (Self et al., 2004) and protein levels (Knackstedt et al., 2010) of Nptx2. In contrast, repeated experimenter-delivered cocaine did not alter Nptx2 protein expression in the accumbens (Lu et al., 2002). Nptx2 appears to alter the behavioral response to cocaine given that global KO of Nptx2 enhances place preference for cocaine but also slows the development of cocaine-induced locomotor sensitization, perhaps by altering the sensitivity to glutamate (Pacchioni et al., 2009). The overlap between the present and previous work identifying genes associated with cocaine-related neuronal and behavioral plasticity bolsters confidence in the relevance of the current empirical results as well as motif and ontology analyses.

RNA sequencing also identified upregulated gene expression of two novel targets not previously known to be involved in cocaine self-administration: VGF and Pmepal. The VGF gene is expressed relatively selectively in the brain. VGF, which curiously is not an acronym, codes for a peptide that shares similarities with the granin family of secreted proteins (Borges et al., 2013). The expression of $V G F$ is upregulated by neurotrophins, including BDNF (Alder et al., 2003), and VGF increases hippocampal neurogenesis (Thakker-Varia et al., 2007; Yang et al., 2016) and synaptic plasticity (Alder et al., 2003). Moreover, VGF KO mice have impaired spatial and fear memory (Bozdagi et al., 2008; Lin et al., 2015). Particularly relevant to the current gene ontology findings, VGF also promotes hippocampal dendritic outgrowth, branching, and spine density (Behnke et al., 2017). Thus, VGF may play 


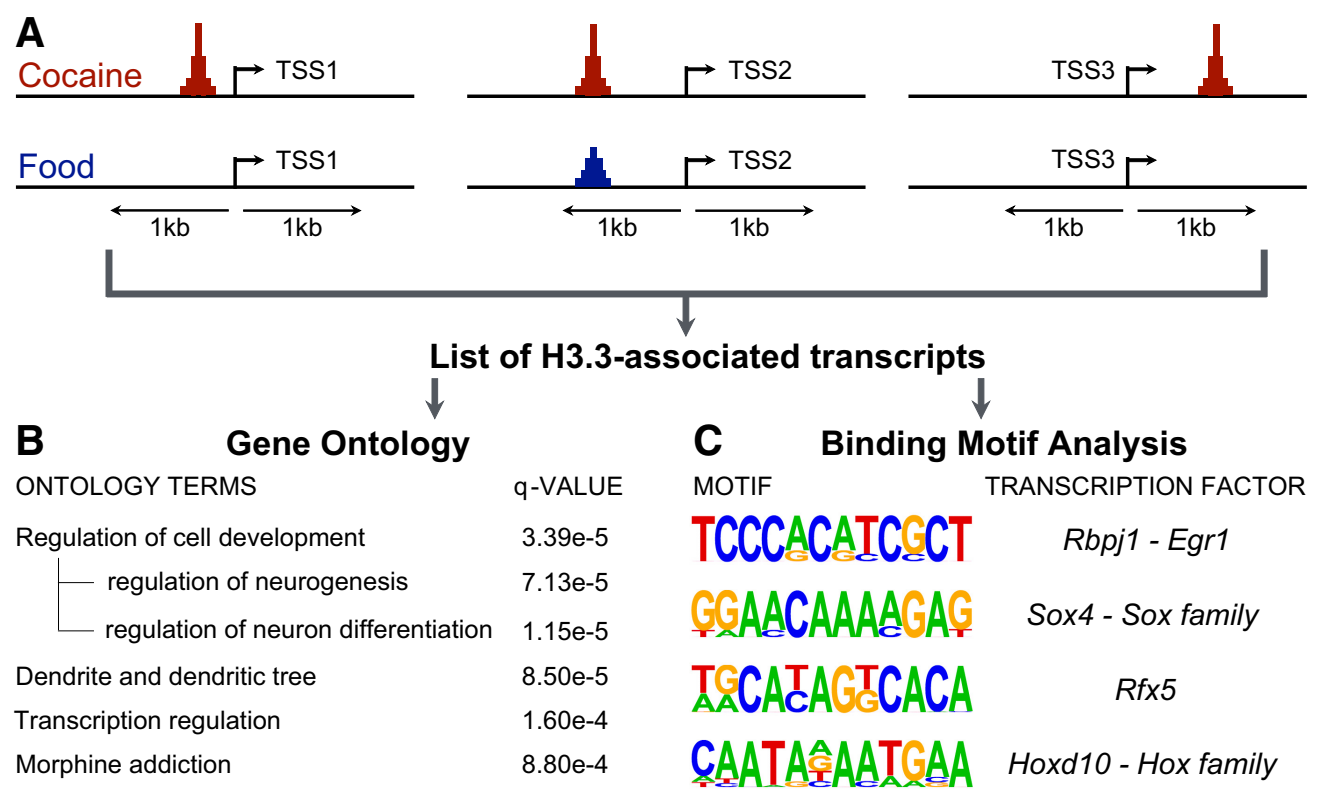

Figure 3. H3.3-HA cocaine-specific accumulation near TSSs reveals potential functions and regulators of cocaine-induced transcripts. A set of transcripts exhibiting cocaine-specific H3.3 differential accumulation within $1 \mathrm{~kb}$ of the TSS was constructed. $A$, The diagram provides examples of $\mathrm{H} 3.3$ differential accumulation that were observed: accumulation within $1 \mathrm{~kb}$ upstream of the TSS (left), difference in magnitude at the same site (middle), or accumulation within $1 \mathrm{~kb}$ downstream of the TSS (right). Gene ontology analysis and de novo binding motif discovery were performed on the list of transcripts with H3.3-HA incorporation following cocaine versus food self-administration. B, Significantly enriched ontology terms and $q$ value are listed. C, Four motifs that could be associated with known transcription factors were overrepresented in cocaine-enriched loci. Figure 3-1 (available at https://doi.org/10.1523/JNEUROSCI.0015-19.2019.f3-1): Peaks of H3.3-HA cocaine-induced accumulation within $1 \mathrm{~kb}$ of annotated transcription start sites.

a role in neurotrophin-mediated increases in accumbens dendritic spine density related to cocaine administration (Anderson et al., 2017). The other novel target identified in this study, Pmepa1, a member of the TGF- $\beta$ family, modulates cell proliferation and differentiation as well as immune responses, and is thus often studied in the context of cancer (Itoh and Itoh, 2018). In the brain, Pmepal expression is increased by activin A, another TGF- $\beta$ family member, and inhibits activin A signaling by decreasing phosphorylation of SMAD2/3 in a negative feedback loop (Link et al., 2016). To our knowledge, no studies have explored Pmepal in response to cocaine; however, activin signaling via SMAD3 is increased following withdrawal from cocaine selfadministration, and SMAD3 mediates cocaine-induced plasticity in dendritic spines in the NAcc (Gancarz et al., 2015). It is possible, therefore, that Pmepa1 overexpression indirectly influences cocaine-elicited dendrite morphogenesis and synaptic plasticity. Notably, Pmepal was the only differentially expressed gene that was not detected in H3.3-HA ChIP-seq analyses due to its specific localization in microglia (Butovsky et al., 2014), a cell type for which active transcription in which would not be captured by the neuron-specific H3.3-HA transgenic mouse model.

Our experiments yielded five significantly differentially expressed genes using a conservative approach, which generated fewer targets than a similar recent sequencing study focused on cocaine-responsive genes (Walker et al., 2018). However, the comparison of cocaine to food self-administration (as opposed to saline) controls for the potential effect of operant learning and operant behavior on gene expression. Thus, we would not expect to see differential expression of genes involved in motor responses or general reinforcing aspects of operant self-administration, which may account for this distinction. We chose this experimental design to specifically uncover genes with high potential as therapeutic targets for cocaine addiction. Encouragingly, our analyses identified known and validated molecules related to cocaine exposure as well as novel transcripts, which represent promising avenues for further research.

A distinct advantage of the H3.3-HA barcoding approach is that it captures cumulative active transcription. Thus, the subset of 2110 transcripts, 1107 of which belong to well-characterized genes, which were differentially associated with $\mathrm{H} 3.3-\mathrm{HA}$ nucleosomes but did not differ in expression following cocaine versus food self-administration, likely underwent temporally limited active transcription. For example, expression of discrete genes associated with the acquisition of cocaine self-administration may be augmented very early in the paradigm and normalize as cocaine self-administration is maintained over time; these genes would not be detected by RNA-seq conducted only following extended cocaine self-administration, and yet present differential H3.3 accumulation. In this experiment, the H3.3-HA transgene expression was suppressed using doxycycline, which was previously shown to fully prevent expression of the HA tag (McNally et al., 2016). Doxycycline was removed at weaning, so it is likely that the tagged version of $\mathrm{H} 3.3$ was incorporated into regions that had active transcription before the onset of either food or cocaine self-administration. We posit that these sites would be similar between the two groups because all mice were housed under similar conditions. Therefore, these nonspecific insertions events likely had no influence on our H3.3-HA ChIP seq analyses. We performed gene ontology and binding motif analyses to identify molecular pathways regulated by cocaine over the course of selfadministration in NAcc neurons. Encouragingly, regulation of cell development, dendrites, and transcription emerged as enriched ontology terms, which is generally consistent with previous reports examining cocaine-induced transcription (Nestler, 1997; Russo et al., 2009; Maze and Nestler, 2011; Walker et al., 2018) as well as the known functions of the three transcription factor binding sites enriched in the HA ChIP-seq peaks: Egr1, Sox4, and Rbpj1. Indeed, all three of these transcription factors 
are critical regulators of cell development, neuronal differentiation, dendritic formation, and synaptic plasticity.

Egr1, also known as Zif268 and Krox24, has long been associated with cocaine exposure and plays a functional role in cocaine reward (Hope et al., 1992; Moratalla et al., 1992; Valjent et al., 2006). Egr 1 expression in the NAcc increases in response to acute cocaine, but Egr1 is suppressed following repeated cocaine administration (Bhat et al., 1992; Hammer and Cooke, 1996). Thus, the emergence of Egr1 binding motifs in H3.3 enriched genomic loci in cocaine exposed animals validates the H3.3-HA ChIP-seq approach as a way to identify genes that may be upregulated during the early but not later phases of cocaine self-administration. The Sox family of transcription factors are known to be key developmental regulators (Julian et al., 2017). Enrichment for Sox 4 binding sites is therefore consistent with the terms related to regulation of cell development, neurogenesis, and dendrite formation that were identified by the ontology analysis. Interestingly, the Sox family of transcription factors have also been associated with the regulation of $\mu$ opioid receptors and addiction (Im et al., 2001; Hwang et al., 2003, 2004). The third transcription factor identified, Rbpj1, is a member of a family of molecules that are an integral part of Notch signaling, which regulates cell differentiation, cell fate, and neural progenitor selfrenewal (Roese-Koerner et al., 2017). Interestingly, Rbpj1 also regulates dopamine responsiveness in the striatum and may be a predictor of vulnerability to psychiatric disease (Toritsuka et al., 2017). Overall, the ontology and binding motif analyses identified established and novel pathways in neurons that are associated with volitional cocaine consumption. These signaling networks represent promising avenues for further research into improving therapeutics for the treatment of addiction.

In conclusion, these findings validate $\mathrm{H} 3.3$ barcoding as a novel tool to delineate changes in transcription elicited by environmental perturbations over extended periods of time in genetically defined cell populations. Our findings validated several known molecular pathways associated with cocaine exposure and revealed novel genes and transcription factors that may be involved in the development of addiction-like behaviors in rodent models.

\section{References}

Ahmad K, Henikoff S (2002) The histone variant H3.3 marks active chromatin by replication-independent nucleosome assembly. Mol Cell 9:1191-1200.

Alder J, Thakker-Varia S, Bangasser DA, Kuroiwa M, Plummer MR, Shors TJ, Black IB (2003) Brain-derived neurotrophic factor-induced gene expression reveals novel actions of VGF in hippocampal synaptic plasticity. J Neurosci 23:10800-10808.

Anderson EM, Wissman AM, Chemplanikal J, Buzin N, Guzman D, Larson EB, Neve RL, Nestler EJ, Cowan CW, Self DW (2017) BDNF-TrkB controls cocaine-induced dendritic spines in rodent nucleus accumbens dissociated from increases in addictive behaviors. Proc Natl Acad Sci U S A 114:9469-9474.

Anderson SM, Famous KR, Sadri-Vakili G, Kumaresan V, Schmidt HD, Bass CE, Terwilliger EF, Cha JH, Pierce RC (2008) CaMKII: a biochemical bridge linking accumbens dopamine and glutamate systems in cocaine seeking. Nat Neurosci 11:344-353.

Bano D, Piazzesi A, Salomoni P, Nicotera P (2017) The histone variant H3.3 claims its place in the crowded scene of epigenetics. Aging (Albany NY) 9:602-614.

Behnke J, Cheedalla A, Bhatt V, Bhat M, Teng S, Palmieri A, Windon CC, Thakker-Varia S, Alder J (2017) Neuropeptide VGF promotes maturation of hippocampal dendrites that is reduced by single nucleotide polymorphisms. Int J Mol Sci 18:E612.

Bejar R, Yasuda R, Krugers H, Hood K, Mayford M (2002) Transgenic calmodulin-dependent protein kinase II activation: dose-dependent ef- fects on synaptic plasticity, learning, and memory. J Neurosci 22:5719-5726.

Berger SL (2007) The complex language of chromatin regulation during transcription. Nature 447:407-412.

Bhat RV, Cole AJ, Baraban JM (1992) Chronic cocaine treatment suppresses basal expression of zif268 in rat forebrain: in situ hybridization studies. J Pharmacol Exp Ther 263:343-349.

Borges R, Dominguez N, Smith CB, Bandyopadhyay GK, O'Connor DT, Mahata SK, Bartolomucci A (2013) Granins and catecholamines: functional interaction in chromaffin cells and adipose tissue. Adv Pharmacol 68:93-113.

Bozdagi O, Rich E, Tronel S, Sadahiro M, Patterson K, Shapiro ML, Alberini CM, Huntley GW, Salton SR (2008) The neurotrophin-inducible gene Vgf regulates hippocampal function and behavior through a brainderived neurotrophic factor-dependent mechanism. J Neurosci 28: 9857-9869.

Briand LA, Kimmey BA, Ortinski PI, Huganir RL, Pierce RC (2014) Disruption of glutamate receptor-interacting protein in nucleus accumbens enhances vulnerability to cocaine relapse. Neuropsychopharmacology 39:759-769.

Butovsky O, Jedrychowski MP, Moore CS, Cialic R, Lanser AJ, Gabriely G, Koeglsperger T, Dake B, Wu PM, Doykan CE, Fanek Z, Liu L, Chen Z, Rothstein JD, Ransohoff RM, Gygi SP, Antel JP, Weiner HL (2014) Identification of a unique TGF-beta-dependent molecular and functional signature in microglia. Nat Neurosci 17:131-143.

Chandra R, Lobo MK (2017) Beyond neuronal activity markers: select immediate early genes in striatal neuron subtypes functionally mediate psychostimulant addiction. Front Behav Neurosci 11:112.

Daury L, Chailleux C, Bonvallet J, Trouche D (2006) Histone H3.3 deposition at E2F-regulated genes is linked to transcription. EMBO Rep 7:6671.

Dobin A, Davis CA, Schlesinger F, Drenkow J, Zaleski C, Jha S, Batut P, Chaisson M, Gingeras TR (2013) STAR: ultrafast universal RNA-sec aligner. Bioinformatics 29:15-21.

Feng J, Wilkinson M, Liu X, Purushothaman I, Ferguson D, Vialou V, Maze I, Shao N, Kennedy P, Koo J, Dias C, Laitman B, Stockman V, LaPlant Q, Cahill ME, Nestler EJ, Shen L (2014) Chronic cocaine-regulated epigenomic changes in mouse nucleus accumbens. Genome Biol 15:R65.

Gancarz AM, Wang ZJ, Schroeder GL, Damez-Werno D, Braunscheidel KM, Mueller LE, Humby MS, Caccamise A, Martin JA, Dietz KC, Neve RL, Dietz DM (2015) Activin receptor signaling regulates cocaine-primed behavioral and morphological plasticity. Nat Neurosci 18:959-961.

Goldberg AD, Banaszynski LA, Noh KM, Lewis PW, Elsaesser SJ, Stadler S, Dewell S, Law M, Guo X, Li X, Wen D, Chapgier A, DeKelver RC, Miller JC, Lee YL, Boydston EA, Holmes MC, Gregory PD, Greally JM, Rafii S, et al. (2010) Distinct factors control histone variant H3.3 localization at specific genomic regions. Cell 140:678-691.

Groves PM (1983) A theory of the functional organization of the neostriatum and the neostriatal control of voluntary movement. Brain Res 286: 109-132.

Haber SN (2003) The primate basal ganglia: parallel and integrative networks. J Chem Neuroanat 26:317-330.

Hake SB, Allis CD (2006) Histone H3 variants and their potential role in indexing mammalian genomes: the "H3 barcode hypothesis." Proc Natl Acad Sci U S A 103:6428-6435.

Hammer RP Jr, Cooke ES (1996) Sensitization of neuronal response to cocaine during withdrawal following chronic treatment. Neuroreport 7:2041-2045.

Heinz S, Benner C, Spann N, Bertolino E, Lin YC, Laslo P, Cheng JX, Murre C, Singh H, Glass CK (2010) Simple combinations of lineage-determining transcription factors prime cis-regulatory elements required for macrophage and B cell identities. Mol Cell 38:576-589.

Hope B, Kosofsky B, Hyman SE, Nestler EJ (1992) Regulation of immediate early gene expression and AP-1 binding in the rat nucleus accumbens by chronic cocaine. Proc Natl Acad Sci U S A 89:5764-5768.

Hwang CK, Wu X, Wang G, Kim CS, Loh HH (2003) Mouse mu opioid receptor distal promoter transcriptional regulation by SOX proteins. J Biol Chem 278:3742-3750.

Hwang CK, Kim CS, Choi HS, McKercher SR, Loh HH (2004) Transcriptional regulation of mouse mu opioid receptor gene by PU.1. J Biol Chem 279:19764-19774.

Im HJ, Smirnov D, Yuhi T, Raghavan S, Olsson JE, Muscat GE, Koopman P, 
Loh HH (2001) Transcriptional modulation of mouse mu-opioid receptor distal promoter activity by Sox18. Mol Pharmacol 59:1486-1496.

Itoh S, Itoh F (2018) TMEPAI family: involvement in regulation of multiple signalling pathways. J Biochem 164:195-204.

Jaenisch R, Bird A (2003) Epigenetic regulation of gene expression: how the genome integrates intrinsic and environmental signals. Nat Genet 33 [Suppl]:245-254.

Julian LM, McDonald AC, Stanford WL (2017) Direct reprogramming with SOX factors: masters of cell fate. Curr Opin Genet Dev 46:24-36.

Kelly MP, Stein JM, Vecsey CG, Favilla C, Yang X, Bizily SF, Esposito MF, Wand G, Kanes SJ, Abel T (2009) Developmental etiology for neuroanatomical and cognitive deficits in mice overexpressing Galphas, a G-protein subunit genetically linked to schizophrenia. Mol Psychiatry 14:398-415, 347.

Knackstedt LA, Moussawi K, Lalumiere R, Schwendt M, Klugmann M, Kalivas PW (2010) Extinction training after cocaine self-administration induces glutamatergic plasticity to inhibit cocaine seeking. J Neurosci 30:7984-7992.

Lin WJ, Jiang C, Sadahiro M, Bozdagi O, Vulchanova L, Alberini CM, Salton SR (2015) VGF and its C-terminal peptide TLQP-62 regulate memory formation in hippocampus via a BDNF-TrkB-dependent mechanism. J Neurosci 35:10343-10356.

Link AS, Kurinna S, Havlicek S, Lehnert S, Reichel M, Kornhuber J, Winner B, Huth T, Zheng F, Werner S, Alzheimer C (2016) Kdm6b and Pmepal as targets of bioelectrically and behaviorally induced activin A signaling. Mol Neurobiol 53:4210-4225.

Love MI, Huber W, Anders S (2014) Moderated estimation of fold change and dispersion for RNA-seq data with DESeq2. Genome Biol 15:550.

Lu W, Marinelli M, Xu D, Worley PF, Wolf ME (2002) Amphetamine and cocaine do not increase Narp expression in rat ventral tegmental area, nucleus accumbens or prefrontal cortex, but Narp may contribute to individual differences in responding to a novel environment. Eur J Neurosci 15:2027-2036.

Mallei A, Ieraci A, Corna S, Tardito D, Lee FS, Popoli M (2018) Global epigenetic analysis of BDNF Val66Met mice hippocampus reveals changes in dendrite and spine remodeling genes. Hippocampus 28: 783-795.

Mayford M, Bach ME, Huang YY, Wang L, Hawkins RD, Kandel ER (1996) Control of memory formation through regulated expression of a CaMKII transgene. Science 274:1678-1683.

Maze I, Nestler EJ (2011) The epigenetic landscape of addiction. Ann N Y Acad Sci 1216:99-113.

Maze I, Covington HE 3rd, Dietz DM, LaPlant Q, Renthal W, Russo SJ, Mechanic M, Mouzon E, Neve RL, Haggarty SJ, Ren Y, Sampath SC, Hurd YL, Greengard P, Tarakhovsky A, Schaefer A, Nestler EJ (2010) Essential role of the histone methyltransferase G9a in cocaine-induced plasticity. Science 327:213-216.

Maze I, Wenderski W, Noh KM, Bagot RC, Tzavaras N, Purushothaman I, Elsässer SJ, Guo Y, Ionete C, Hurd YL, Tamminga CA, Halene T, Farrelly L, Soshnev AA, Wen D, Rafii S, Birtwistle MR, Akbarian S, Buchholz BA, Blitzer RD, et al. (2015) Critical role of histone turnover in neuronal transcription and plasticity. Neuron 87:77-94.

McNally AG, Poplawski SG, Mayweather BA, White KM, Abel T (2016) Characterization of a novel chromatin sorting tool reveals importance of histone variant $\mathrm{H} 3.3$ in contextual fear memory and motor learning. Front Mol Neurosci 9:11.

Moratalla R, Robertson HA, Graybiel AM (1992) Dynamic regulation of NGFI-A (zif268, egr1) gene expression in the striatum. J Neurosci 12:2609-2622.

Nestler EJ (1997) Molecular mechanisms of opiate and cocaine addiction. Curr Opin Neurobiol 7:713-719.

Nestler EJ (2004) Molecular mechanisms of drug addiction. Neuropharmacology 47 [Suppl 1]:24-32.

Ortinski PI, Briand LA, Pierce RC, Schmidt HD (2015) Cocaine-seeking is associated with PKC-dependent reduction of excitatory signaling in accumbens shell D2 dopamine receptor-expressing neurons. Neuropharmacology 92C:80-89.

Pacchioni AM, Vallone J, Worley PF, Kalivas PW (2009) Neuronal pentraxins modulate cocaine-induced neuroadaptations. J Pharmacol Exp Ther 328:183-192.
Pelkey KA, Barksdale E, Craig MT, Yuan X, Sukumaran M, Vargish GA, Mitchell RM, Wyeth MS, Petralia RS, Chittajallu R, Karlsson RM, Cameron HA, Murata Y, Colonnese MT, Worley PF, McBain CJ (2015) Pentraxins coordinate excitatory synapse maturation and circuit integration of parvalbumin interneurons. Neuron 85:1257-1272.

Pierce RC, Wolf ME (2013) Psychostimulant-induced neuroadaptations in nucleus accumbens AMPA receptor transmission. In: Addiction (Pierce RC, Kenny PJ, eds), pp 121-134. Cold Spring Harbor, NY: Cold Spring Harbor Laboratory.

Pierce RC, Fant B, Swinford-Jackson SE, Heller EA, Berrettini WH, Wimmer ME (2018) Environmental, genetic and epigenetic contributions to cocaine addiction. Neuropsychopharmacology 43:1471-1480.

Renthal W, Nestler EJ (2008) Epigenetic mechanisms in drug addiction. Trends Mol Med 14:341-350.

Renthal W, Kumar A, Xiao G, Wilkinson M, Covington HE 3rd, Maze I, Sikder D, Robison AJ, LaPlant Q, Dietz DM, Russo SJ, Vialou V, Chakravarty S, Kodadek TJ, Stack A, Kabbaj M, Nestler EJ (2009) Genomewide analysis of chromatin regulation by cocaine reveals a role for sirtuins. Neuron 62:335-348.

Roese-Koerner B, Stappert L, Brustle O (2017) Notch/Hes signaling and miR-9 engage in complex feedback interactions controlling neural progenitor cell proliferation and differentiation. Neurogenesis (Austin) 4:e1313647.

Russo SJ, Wilkinson MB, Mazei-Robison MS, Dietz DM, Maze I, Krishnan V, Renthal W, Graham A, Birnbaum SG, Green TA, Robison B, Lesselyong A, Perrotti LI, Bolaños CA, Kumar A, Clark MS, Neumaier JF, Neve RL, Bhakar AL, Barker PA, et al. (2009) Nuclear factor kappa B signaling regulates neuronal morphology and cocaine reward. J Neurosci 29:3529-3537.

Self DW, Choi KH, Simmons D, Walker JR, Smagula CS (2004) Extinction training regulates neuroadaptive responses to withdrawal from chronic cocaine self-administration. Learn Mem 11:648-657.

Solà C, Tusell JM, Serratosa J (1999) Comparative study of the distribution of calmodulin kinase II and calcineurin in the mouse brain. J Neurosci Res 57:651-662.

Strahl BD, Allis CD (2000) The language of covalent histone modifications. Nature 403:41-45.

Taniguchi M, Carreira MB, Cooper YA, Bobadilla AC, Heinsbroek JA, Koike N, Larson EB, Balmuth EA, Hughes BW, Penrod RD, Kumar J, Smith LN, Guzman D, Takahashi JS, Kim TK, Kalivas PW, Self DW, Lin Y, Cowan CW (2017) HDAC5 and its target gene, Npas4, function in the nucleus accumbens to regulate cocaine-conditioned behaviors. Neuron 96:130-144.e6.

Thakker-Varia S, Krol JJ, Nettleton J, Bilimoria PM, Bangasser DA, Shors TJ, Black IB, Alder J (2007) The neuropeptide VGF produces antidepressantlike behavioral effects and enhances proliferation in the hippocampus. J Neurosci 27:12156-12167.

Toritsuka M, Kimoto S, Muraki K, Kitagawa M, Kishimoto T, Sawa A, Tanigaki K (2017) Regulation of striatal dopamine responsiveness by Notch/ RBP-J signaling. Transl Psychiatry 7:e1049.

Valjent E, Aubier B, Corbillé AG, Brami-Cherrier K, Caboche J, Topilko P, Girault JA, Hervé D (2006) Plasticity-associated gene Krox24/Zif268 is required for long-lasting behavioral effects of cocaine. J Neurosci 26 : 4956-4960.

Walker DM, Cates HM, Loh YE, Purushothaman I, Ramakrishnan A, Cahill KM, Lardner CK, Godino A, Kronman HG, Rabkin J, Lorsch ZS, Mews P, Doyle MA, Feng J, Labonté B, Koo JW, Bagot RC, Logan RW, Seney ML, Calipari ES, et al. (2018) Cocaine self-administration alters transcriptome-wide responses in the brain's reward circuitry. Biol Psychiatry 84:867-880.

Yang D, Zhang W, Padhiar A, Yue Y, Shi Y, Zheng T, Davis K, Zhang Y, Huang M, Li Y, Sha L (2016) NPAS3 regulates transcription and expression of VGF: implications for neurogenesis and psychiatric disorders. Front Mol Neurosci 9:109.

Zhang D, Zhang L, Lou DW, Nakabeppu Y, Zhang J, Xu M (2002) The dopamine $\mathrm{D} 1$ receptor is a critical mediator for cocaine-induced gene expression. J Neurochem 82:1453-1464.

Zhang Y, Liu T, Meyer CA, Eeckhoute J, Johnson DS, Bernstein BE, Nusbaum C, Myers RM, Brown M, Li W, Liu XS (2008) Model-based analysis of ChIP-seq (MACS). Genome Biol 9:R137. 